\title{
Case-Based Clinical Reasoning And Decision Making Model
}

\author{
Olgu Temelli Klinik Akıl Yürütme ve Karar Verme Modeli
}

\author{
Ali Ihsan Tasci ${ }^{1}$, Esra Akdeniz ${ }^{2}$ \\ 1 University of Health Sciences, Bakırköy Dr. Sadi Konuk Training and Research Hospital, Department of Urology, Istanbul, Turkey \\ 2 Marmara University, Faculty of Medicine, Basic Medical Sciences, Istanbul, Turkey
}

Geliş tarihi (Submitted): 2020-07-28 Kabul tarihi (Accepted): 2020-11-11

\begin{abstract}
Yazışma / Correspondence Ali Ihsan Tasci

Zuhuratbaba Mah. Dr. Tevfik Sağlam Cd. N:11, 34147, Istanbul / Turkey E mail: aliihsantasci@hotmail.com GSM: +90 5322328375
\end{abstract}

\section{ORCID}

A.I.T. $\quad$ 0000-0002-6943-6676 E.A. $\quad 0000-0002-3549-5416$

This work is licensed under a Creative Commons Attribution-NonCommercial 4.0 International License.

\section{Özet}

Amaç: Klinik akıl yürütme, klinik uygulamalarda doğru karar verebilmek için gerekli bir yeterliktir. Olguların yönetilmesi için olgunun çözümlenmesi, nedenlerin tespiti, bunlar arasında olguyla uyumlu olan ve olmayanların değerlendirilmesi, kanıtların aranması için amaca uygun muayene ve araştırmaların yapılması ve bunların sonuçlarının yorumlanması, nihayetinde ile tanı ve çözümlerin ortaya konulması gerekmektedir. Olgu temelli öğrenme ve değerlendirme, klinik akıl yürütme tanımlanmalarında ve metodolojilerinde konsensüs mevcut değildir ve uygulamalar eğiticiler ve kurumların kültürlerine göre şekillenmektedir. Olgunun çözümünde, klinik akıl yürütme ve karar vermeyi odağına alan aşamalandırılmış, kolay kullanılabilir, değerlendirme formlarına da uygun bir modele ihtiyaç mevcuttur. Bu çalışmanın amacı, olgu temelli klinik akıl yürütme ve karar verme modelini tanıtmak ve etkinliğini değerlendirmektir.

Gereç ve Yöntemler: Sağlık Bilimleri Üniversitesi Bakırköy Dr. Sadi Konuk Eğitim ve Araştırma Hastanesi, Üroloji Kliniğinde uzmanlık eğitimi alan 13 öğrenci ve Sağlık Bilimleri Üniversitesi ile afiliye İstanbul'daki Eğitim ve Araştırma Hastanelerinde, eğitiminden sorumlu 14 eğitici çalışmaya dahil edilmiştir.

Mezuniyet sonrası uzmanlık eğitiminde, ögrencilere ve eğiticilere modelin tanıtımı ve uygulama yöntemleri konusunda eğitim verildikten sonra metodun uygulanması istenmiştir. Uygulamalar sonrasında eğiticiler ve öğrencilere modelin kullanışlılığı ve öğrenme algıları hakkında değerlendirme anketi yapılmıştır.

Bulgular: Eğitici ve öğrencilerin model hakkındaki görüssleri, modelin kolaylıkla anlaşıldığı, klinikte karşılaşılan vakalarda kolaylıkla uygulandığı̆, olguların çözümünde sistematik bir yaklaşım sağladığı, ayrıcı tanı yapmayı kolaylaştırdığı, çok

\section{Abstract}

Objective: Clinical reasoning is a necessary competence to make the right decision in clinical practice. In order to manage the cases, it is necessary to analyze the case, to determine the causes, to evaluate among those who are compatible with the case and to evaluate the results, to perform appropriate examinations and researches for the purpose, to interpret their results, to eventually exclude and calculate the probabilities, and to identify the diagnosis and solutions. In these processes, clinical reasoning and appropriate decisions are made. There is no consensus in casebased learning and evaluation, clinical reasoning definitions and methodologies, and practices are shaped according to the culture of educators and institutions. In the solution of the case, there is a need for a staged, easy-to-use and evaluation-appropriate model that focuses on clinical reasoning and decision making. Aim of the study, to introduce a case-based clinical reasoning and decision making model and evaluate its effectiveness.

Materials and Methods: University of Health Sciences Bakırköy. Sadi Konuk Training and Research Hospital, 13 students who received specialization training in the Urology Clinic, and 14 trainers responsible for their education in the Health Sciences University and Affiliated Training and Research Hospitals were included in the study. In post-graduate specialization training, students and educators were asked to apply the method after training on the introduction of the model and application methods. After the applications, an evaluation questionnaire about the usefulness of the model and perceptions of learning was conducted to the trainers and students.

Results: The opinions of the educators and students about the model, the model is easily understood, it is easily applied in cases encountered in the clinic, it provides a systematic approach to 
yönlü bakış açısı sağladığı, hata yapma olasılığını azalttığı, karar verirken nedenini düșünmeyi sağladığı, gereksiz ișlemler yapılmasını önlediği yönünde bulundu. Öğrenciler model ile ilgili bilgi düzeylerini anlayabildiklerini ve öğrenme motivasyonunu artırdı̆̆ını belirtmişlerdir. Eğiticiler modeli uygulamak için hazırlık zamanı diğer yöntemlerden fazla olduğunu, öğrencilerin olguyu çözme sorumluluğunu aldıklarını, model ile öğrencilerin bilgi düzeylerini ve eksikliklerinin daha kolay anlaşılabildiğini, geri bildirim vermeyi kolaylaştırdığı ve değerlendirmenin objektifliğini sağladığını yüksek oranda belirtmişlerdir.

Sonuç: Olgu temelli klinik akıl yürütme ve karar vermenin, eğitici ve öğrencilerin ortaklaştığı model ile yapılması halinde öğrencinin hata yapma, gereksiz inceleme ve müdahale yapma ihtimalleri azalacak, yaptıklarını bilerek/kanıta uygun yapma becerisi artacaktır

Anahtar Kelimeler: klinik akıl yürütme, olgu temelli çalışma, tıp eğitimi the solution of the cases, it makes it easier to make differential diagnosis, it provides a versatile perspective, it reduces the possibility of making mistakes, it makes it possible to think about the reason when making decisions, and prevents unnecessary operations, found direction. The students stated that they could understand their knowledge about the model and increase their motivation to learn. The trainers have stated that preparation time for applying the model is more than other methods, students take responsibility for solving the case, the level of knowledge and deficiencies of the model and students are more easily understood, facilitating feedback and providing objectivity of the evaluation.

Conclusion: If the case-based clinical reasoning and decision-making is made with the model that the educators and the students share, the possibility of malpractices, unnecessary examinations and interventions will be reduced, and the ability to make more conscious and evidence-based decisions will be increased.

Keywords: clinical reasoning, case based study, medical education

\section{Gíriş}

Olgu temelli öğrenme, tartışma ve değerlendirme, probleme dayalı öğrenme, iş başında öğrenme ve değerlendirme ve benzeri öğrenci merkezli eğitim aktivitelerinin hemen tamamının odağında olgu mevcuttur. $\mathrm{Bu}$ uygulamalarda gereken temel yeterlik klinik akıl yürütmedir.

Klinik akıl yürütme, çeşitli şekillerde tanımlanmaktadır. Hasta bilgileri ve bulguları ile hekimin temel bilgileri ve deneyimlerinin, problemin çözümünde kullanma süreçleri (1), hastaların tanı ve tedavisi için klinisyenlerin verileri gözlemlediği, topladığ 1 ve yorumladığı bir beceri, süreç ve ya sonuçları (2), hasta hikayesi, muayene ve incelemelerden elde edilen bilgilerin toplanması, analizi ile hastanın probleminin ve ya klinik durumunun ortaya konulması, çözüm için gerekli plan ve uygulamaların yapılması, sonuçların değerlendirilmesi, refleksiyonlar yapılması süreçleri (3) olarak tanımlamalar yapılmıştır.

Klinik akıl yürütmeyi, klinik süreçlerde, indirgemeci olmayan, çok boyutlu, ön yargılardan uzak düşünme ve karar verme becerisi olarak tanımlayabiliriz.

Klinik akıl yürütme hekimin sahip olması gereken temel bir yeterliktir. Tibbi hataların çoğunda klinik akıl yürütme süreçlerinin eksikliği söz konusu olmaktadır. Klinik akıl yürütme becerisi hasta güvenliği için şarttır. Sağlıkta gereksiz iş ve işlemlerden kaçınma, şiddet, hasta hekim uyuşmazlıklarında klinik akıl yürütme konusunda beceri eksikliğinin etkisini görmek müm- kündür. Keza hekimlerin yaptıkları işlerden tatmini ve anlam artışı için bu beceri önem taşımaktadır.

Tip eğitiminde, olgular üzerinden yürütülen öğrenme ve değerlendirme aktivitelerinde çok sayıda metot tanımlanmış olmakla birlikte, çeşitli nedenlerle uygulamalarda bu metotlar yeterince kullanılamamaktadır.

Öğrenme ile ilgili teoriler ve yapılmış çalışmalardan yola çıkılarak, klinik ortamların, eğiticilerin ve öğrencilerin özellikleri dikkate alınarak, bireysel, grup ve sinıf ortamlarında, mezuniyet öncesinde ve sonrasında öğrenme ve değerlendirmelerde kullanılabilen, pratik, kolay akılda kalan bir model, tıp eğitimine katkı sağlayacaktır.

\section{MODELIN TANITIMI}

Olgu temelli klinik akıl yürütme ve karar verme modeli beş aşamadır. (Tablo 1) Model hastanın yakınmaları ve klinik durumu açıklayan olgu bilgileri ile başlar.

1.Aşama: $\mathrm{Bu}$ aşamanın ilk basamağında, öğrenci olgu bilgileri ile problem/klinik durumların nedenlerini belirler. Bu ilk hipotez oluşturma aşamasıdır. Daha sonra, olgu bilgileri kullanilarak, belirlenen olgu nedenleri analiz edilir. Kabul veya ret kararları verilir. $\mathrm{Bu}$ hipotezin değerlendirme aşamasıdır. Son basamakta öğrenci, önceki basamakta kabul ettiği olgu nedenleri değerlendirmek için sorulması gereken soruları belirler ve sorar.

2.Aşama: Öğrencinin bir önceki aşamada belirlediği ve sorduğu soruların cevapları özetlenerek başlanır. 
Hastanın yakınmaları/klinik durum ve sorgulamalar sonunda elde edilen bilgilerle olgu nedenlerinin analizi tekrarlanır, kabul veya ret kararları verilir. Bu ikinci hipotez değerlendirmesidir. Bu aşamanın son basamağında olgunun değerlendirilebilmesi, kararlar verilebilmesi için beklenen bulguları belirtilerek yapılması gereken (Fizik muayene, laboratuvar, görüntüleme vb.) incelemeler belirlenir.

3.Aşama: Bir önceki aşamanın sonunda öğrencinin belirlediği muayene, laboratuvar ve görüntülemelerine ait bulgular özetlenerek başlanır. Bulgular ile olgu nedenlerinin analizi yapılır, kabul veya ret kararları verilir. Bu üçüncü Hipotez değerlendirmesidir. Sonunda tanı kararları belirlenir.

4. Aşama: Bu aşamaya önceki aşamada verilen tanı kararları üzerinde eğiticinin rehberliği ile kesinleștirmeler yapılarak başlanır. Bu aşamanın ilk basamağında tanıya göre tedavi seçenekleri belirlenir. Bu tedavi için yeni hipotez oluşturmadır. İkinci basamakta riskleri ve yararları belirleyerek uygun tedavi/yönetim seçimi yapilır. Bu ise tedavi hipotezlerinin değerlendirilmesidir. Son basamak tedavi/yönetim planı ve uygulamalar konusunda kararların verilmesi gerekir.

5.Aşama: Eğiticinin geri bildirim vereceği, değerlendirmeler yapacağ 1 ve öğrenci ile refleksiyon yapacağı aşamadır.

Model ile çalışma, birinci aşamadan başlayarak takip eden aşamalara ilerletilebildiği gibi, ilk aşamalar tamamlanmış işe diğer aşamalardan başlatılabilir. Örneğin tanısı konulmuş bir hastanın tedavisinin yönetilmesi isteniyorsa, model 4. aşamanın başlatılabilir. Model, küçük modifikasyonlarla, hastanın mevcut olduğu iş başında klinik öğrenme ve değerlendirmelerde kullanılabileceği gibi, hastanın olmadığı, olgu temelli öğrenme, tartışma ve değerlendirme oturumlarında kullanılabilir.

Tablo 1. Olgu Temelli Klinik Akıl Yürütme Ve Karar Verme Modeli

\begin{tabular}{|c|c|c|}
\hline 1.aşama & $\begin{array}{l}\text { Olgu } \\
\text { 1. Nedenler } \\
\text { 2. Analiz } \\
\text { 3.Sorgulamalar }\end{array}$ & $\begin{array}{l}\text { Hastanın yakınmaları/klinik durum } \\
\text { Olgu bilgileri ile olguda problem/klinik durumların nedenleri } \\
\text { Olgu bilgileri ile olgu nedenlerinin analizi (kabul veya ret) } \\
\text { Olgunun nedenlerini değerlendirmek sorgulamalar }\end{array}$ \\
\hline 2.aşama & $\begin{array}{l}\text { Yeni bilgiler } \\
\text { 4. Analiz } \\
\text { 5. İncelemeler }\end{array}$ & $\begin{array}{l}\text { Sorgulama sonrası yeni bilgiler } \\
\text { Hastanın yakınmaları/klinik durum ve sorgulamalar sonunda elde edilen bilgilerle } \\
\text { olgu nedenlerinin analizi (kabul veya ret) } \\
\text { Beklenen bulguları ile yapılması gereken (FM, Lab, görüntüleme vb.) incelemeler }\end{array}$ \\
\hline 3.aşama & $\begin{array}{l}\text { Bulgular } \\
\text { 6. Analiz } \\
\text { 7. Tanı kararları }\end{array}$ & $\begin{array}{l}\text { Yapılan incelemelerden elde edilen bulgular } \\
\text { Bulgular ile olgu nedenlerinin analizi (kabul veya ret) }\end{array}$ \\
\hline 4.aşama & $\begin{array}{l}\text { Tanı } \\
\text { 8. Tedavi seçenekleri } \\
\text { 9. Analiz } \\
\text { 10. Tedavi/yönetim }\end{array}$ & $\begin{array}{l}\text { Tanı kararlarımda ortaklaşma } \\
\text { Tanıya göre tedavi seçenekleri } \\
\text { Riskleri ve yararları belirleyerek uygun tedavi/yönetim seçimi } \\
\text { Tedavi/yönetim planı ve uygulamalar }\end{array}$ \\
\hline 5.aşama & $\begin{array}{l}\text { Geri bildirim } \\
\text { Değerlendirme Refleksiyon }\end{array}$ & \\
\hline
\end{tabular}


Şekil 1. Öğrencilerin sorulara verdikleri yanıtların likert grafiği

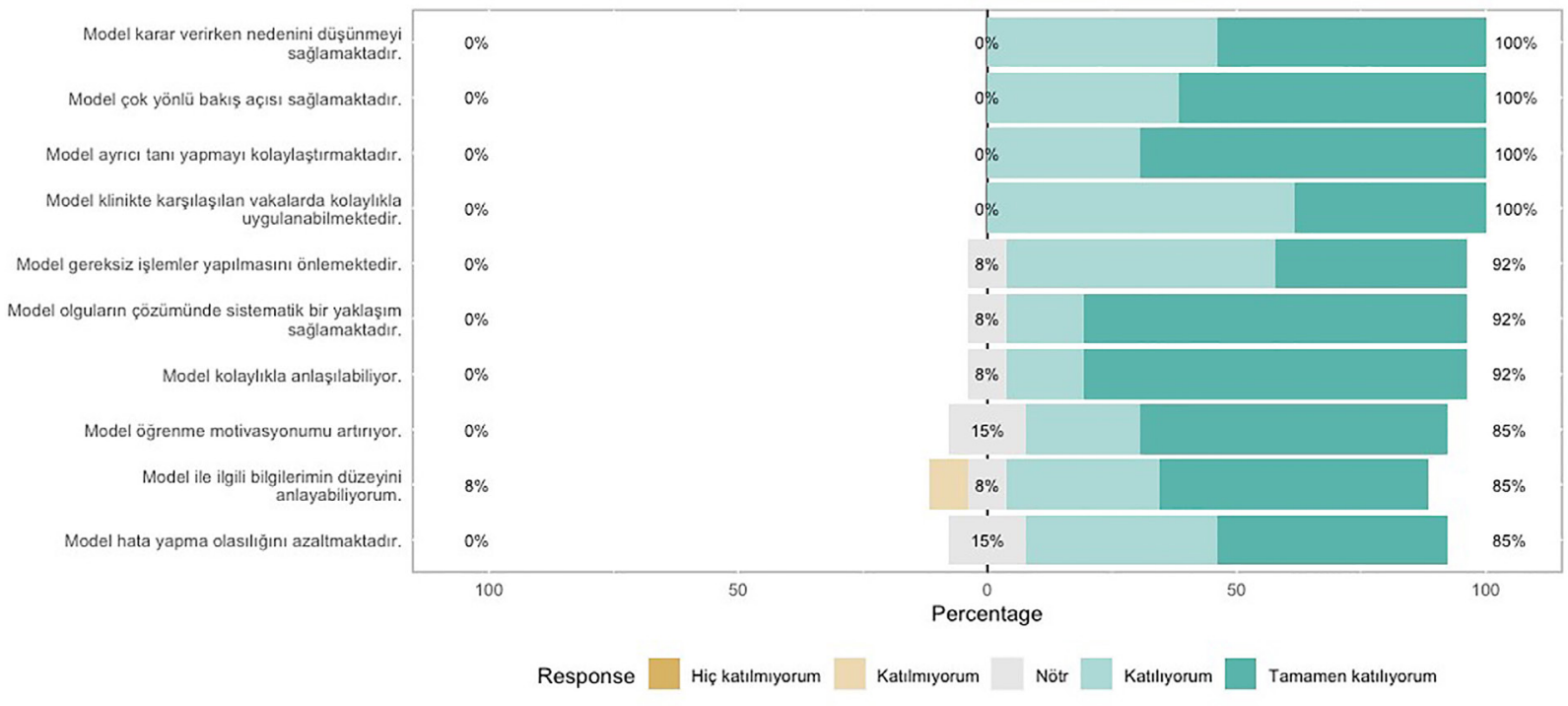

Şekil 2. Eğiticilerin sorulara verdikleri yanıtların likert grafiği

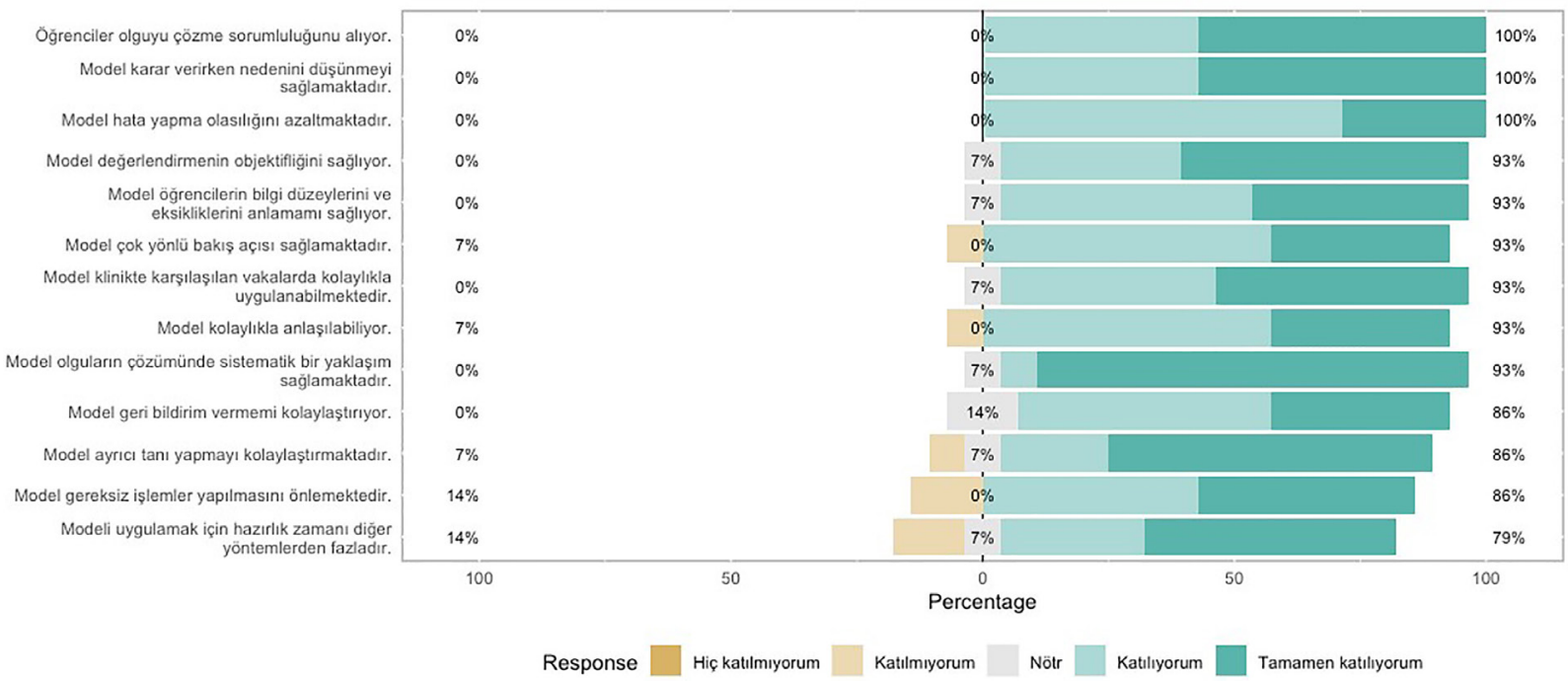

Tablo 2. Öğrenciler ve eğiticiler geri bildirimleri arasındaki farklar

\begin{tabular}{llll}
\hline Ortak Maddeler & Öğrenciler Medyan(IQR) & Eğiticiler Medyan(IQR) & $\mathbf{P}^{*}$ \\
Model kolaylıkla anlaşılabiliyor. & $5(0)$ & $4(1)$ & 0.0578 \\
\hline Model klinikte karşışılan vakalarda kolaylıkla uygulanabilmektedir. & $4(1)$ & $4.5(1)$ & 0.7407 \\
Model olguların çözümünde sistematik bir yaklaşım saptamaktadır. & $5(0)$ & $5(0)$ & 0.6157 \\
Model ayııııı tanı yapmayıı kolaylaştırmaktadır. & $5(1)$ & $5(1)$ & 0.6396 \\
Model çok yönlü bakış açısı sağlamaktadır. & $5(1)$ & $4(1)$ & 0.1606 \\
Model hata yapma olasıllğııı azaltmaktadır. & $5(1)$ & $4(0.75)$ & 0.7623 \\
Model karar verirken nedenini düşünmeyi sağlamaktadır. & $4(1)$ & $5(1)$ & 0.888 \\
Model gereksiz işlemler yapilmasını önlemektedir. & $5(1)$ & $4(1)$ & 0.9786 \\
\hline
\end{tabular}

*:Mann-Whitney U testip değeri 


\section{GEREÇ VE YÖNTEMLER}

Etik kurul onayı alındıktan sonra (Bakırköy Dr. Sadi Konuk EAH, Etik Kurul Kabul Tarihi: 08.06.2020, Karar No:2020-12) Sağlık Bilimleri Üniversitesi Bakırköy Dr. Sadi Konuk Eğitim ve Araştırma Hastanesi, Üroloji Kliniğinde uzmanlık eğitimi alan 6 aylık eğitim süresini tamamlamış 13 öğrenci ve Sağlık Bilimleri Üniversitesi ile afiliye İstanbul'daki Eğitim ve Araştırma Hastanelerinde en az 6 aydır eğiticilik görevi yapan 14 eğitici çalışmaya dahil edilmiştir.

Mezuniyet sonrası uzmanlık eğitiminde, öğrencilere ve eğiticilere modelin teorik çerçevesi, özellikleri, kullanım yöntemi sunulup üç olgu ile uygulama yapıldıktan sonra metodu uygulamaları istenmiştir. Bu eğitimde, metodun Uygulamalar sonrasında eğiticiler ve öğrencilere modelin kullanışlılığı ve öğrenme algıları hakkında 5’li likert ölçeği ile geri bildirimler alınmıştır.

İstatistiksel analizler için R 4.0 programı kullanılmıştır. Sorulara verilen yanıtlar likert grafiğinde yüzde olarak gösterilmiştir. Likert grafikleri için $\mathrm{R}$ programındaki "likert" paketi kullanılmıştır. Öğrenciler ve eğiticilere yöneltilen ortak sorular medyan ve çeyrekler arası açıklık ile özetlenmiştir ve iki grup arasındaki farka Mann-Whitney U testi ile bakılmıştır. $\mathrm{P}<0.05$ istatistiksel olarak anlamlı kabul edilmiştir.

\section{BULGULAR}

Eğitici ve öğrencilerin model hakkındaki görüşleri, modelin kolaylıkla anlaşıldığı, klinikte karşılaşılan vakalarda kolaylıkla uygulandığı, olguların çözümünde sistematik bir yaklaşım sağladığı, ayrıcı tanı yapmayı kolaylaştırdığı, çok yönlü bakış açısı sağladığı, hata yapma olasılığını azalttığı, karar verirken nedenini düşünmeyi sağladığı, gereksiz işlemler yapılmasını önlediği yönünde bulundu.

Öğrencilerin geri bildirimlerine ait Likert grafiğinde sorular en yüksek pozitiften en düşük pozitife doğru sıralanmıştır. Grafiğe göre öğrenciler tüm sorulara yüksek oranda pozitif yanıt vermişlerdir. Özellikle ilk 4 soruda tamamen pozitif eğilimdedirler. Sonraki sorularda az da olsa nötr cevaplar vardır sadece "Model ile ilgili bilgilerimin düzeyini anlayabiliyorum" sorusunda \%8 oranında negatif cevap vardır (Şekil 1).

Eğiticilerin geri bildirimlerine ait grafiğe göre eğiti- ciler, öğrencilerin olguyu çözme konusunda sorumluluk aldıkları, karar verirken nedenini düşünmeyi sağladığı ve hata yapma olasılığını azalttığı konusunda tamamen pozitifler. Hazırlık zamanının diğer yöntemlere göre daha fazla olduğunu düşünmekle birlikte diğer konularda pozitifler (Şekil 2). Öğrenciler ve eğiticilerin ortak sorular hakkındaki görüşleri farkllılı göstermemektedir (Tablo 2).

\section{TARTIŞMA}

Olgu temelli klinik akıl yürütme ve karar verme ile ilgili çeşitli öğrenme ve değerlendirme yöntemleri mevcuttur. Bu yöntemlerin etkin kullanılması için eğiticilerin bilgi ve deneyime sahip olmaları gerekir. $\mathrm{Bu}$ konularda eksiklikler, sağlık hizmeti sunma yükünün fazlalığı, yöntemler için hazırlığın gerekmesi gibi nedenlerle standart ve kılavuzlanmış modellerin kullanımı sinırlıdır. Ancak, belirli bir model kullanılmasa da "Olgudaki problemler nelerdir?”, "Bu klinik bilgiler ile olgunun nedenleri neler olabilir?", "Olgunun nedenlerini analiz edebilmek için başka hangi bilgilere ihtiyacınız var?", "Hangi tanı testler istenmelidir?” İstediğiniz testlerde beklediğiniz bulgular nelerdir ve/veya bu testler hipotezinizin değerlendirmesinde ne işinize yarayacak?", “bu kararınızın gerekçeleri nelerdir?" vb. klinik akıl yürütme ve karar verebilmeyi teşvik eden soru kalıpları, eğiticiler tarafından sıklıkla kullanılmaktadırlar.

Eğitimin aktivitelerinde, ölçme ve değerlendirme uygulamalarında çerçeve modeller, eğiticiler, öğrenciler ve kurum için ortaklaşılan bir alan sağlaması, eğitimin kalitesi için yönünden önemlidir.

Klinik akıl yürütmenin nasıl gerçekleştiği ile ilgili teoriler arasında analitik olmayan (sistem 1), analitik (sistem 2) düşünme ve "dual process" teorileri kabul görmektedir. Analitik olmayan düşünme, hızlı gerçekleşen, fazla bir zihinsel efor gerektirmeyen sezgisel bir düşünmedir. Bu tip düşünme sisteminde kişi, olgular/ olaylar karşısında zihnindeki kodlar (scriptler) ile hızla karar verirler. Deneyimli klinisyenler de olgular karşısında zihindeki hastalık şemaları (ilness scripts) hızla karar verişi bu tip düşünmeye örnektir (4). Analitik düşünmede (sistem 2 düşünme) neden sonuç ilişkisi kurularak sonuca varılır. Rasyonel düşünme biçimidir. 
$\mathrm{Bu}$ düşünme daha yavaştır ve zihinsel eforu gerektirir. Hipotezler oluşturulması ve bunların analizi (hipoteto-deductive) söz konusudur (5). Klinik akıl yürütmenin zihinsel süreçlerinde iki düşünce sisteminin bağımsız olmadığı, birlikte çalıştığı da (dual-process theory) öne sürülmektedir. Her iki sistemin birlikteliği tanısal yeterliği artırdığı kabul edilmektedir $(6,7)$. Rutin tıbbi uygulamalarda analitik-olmayan düşünme tarzı ön plandadır. Bu tarz düşünme genellikle hızl1 ve doğru kararlar verilse de hata yapma ihtimalini barındırmaktadır. Analitik-olmayan düşünme sonucu yetersiz kaldığında analitik düşünme devreye girmekte ve daha doğru karar verilmesi sağlanmaktadır.(8)

$\mathrm{Bu}$ çalışmada, klinik akıl yürütme ve karar verme ile ilgili yukarıda belirtilen teoriler, öneriler, mevcut modeller dikkate alınarak, klinik pratiğe uygun, kolay anlaşılabilir ve hem eğitimde hem de değerlendirmelerde uygulanabilir olarak hazırlanmıştır. Model hakkında eğiticiler ve öğrencilerden alınan geri bildirimler pozitif yönde olduğu görülmektedir.

Olgu temelli öğrenme ile ilgili çalışmaların çoğu öğrenmenin sonuçları, eğiticiler ve öğrencilerin reaksiyonları ve geri bildirimleri ile ilgilidir. Eğiticiler, olgu temelli öğrenme modelleri hakkında pozitif geri bildirimlerde bulunmakta ancak hazırlanmasının ve oturumların zaman alıcı olduğunu bildirmektedirler (9). Bizim çalışmamızda da eğiticiler de hazırlık zamanının diğer yöntemlere göre daha fazla olduğu yönünde görüş bildirmektedirler.

İş basında öğrenme alanında çeşitli öğrenme modelleri geliştirilmiştir. Stanford, SNAPPS ve Beş adında mikrobeceriler (One minute preceptor) modeli en çok bilinen ve kullananlar arasındadir.

SNAPPS modelinde klinikte öğrenim altı adımda tanımlanmıştır. Bunlar hasta karşılaşması/görüşmesi ve alınan öykünün ve fizik muayene bulgularının kısa sunumu (Summarizing), olası tanıların belirlenmesi, ayrıcı tanı listesinin daraltılması (Narrowing), ayrıcını tanının analizi (Analysis), belirsiz, zor, çelişkili durumların ve alternatif yaklaşımların/yolların irdelenmesi (Probe the preceptor), tanilamaya, konsültasyona, tedaviye, kontrole vb. yönelik planlarının oluşturulması
(Plan the management), olgu özelinde öğrenenler için ileri öğrenme/gelişim planlarının oluşturulması (Selection of issues for self-study).aşamalarıdır $(10,11)$.

SNAPP modelinin uygulandığı çalışmada öğrenciler, öğrenme eylemlerinde aktif olduklarını, sezgisel düşünmelerinin arttığını, öğrenmelerinin kolaylaştığını belirtmişlerdir. (10) Uzmanlık eğitiminde SNAPPS modeli ile geleneksel olgu sunumlarının karşılaştırıldığı randomize klinik çalışmada, modelin tanı hipotezleri oluşturma, ayırıcı tanı yapmada etkin olduğunu bildirmişlerdir (12).

Öğrenmede mikrobeceriler modeli one minute preceptör olarak da adlandırılmaktadır. Klinikte, beş dakika veya daha az zaman aralıklarında öğrenmek için çerçeve sunmaktadır. Uzmanlık eğitiminde daha uygun olduğu düşünülse de daha uzun zaman aralıklarında mezuniyet öncesi eğitimde de kullanılabilir (13). One minute preceptor yöntemi ile klasik derslerin karşılaştırıldığı randomize kontrollü çalışmada eğiticiler, yöntemin faydalı olduğunu, eğitici performanslarını ve motivasyonlarını arttırdığını belirtmișlerdir (14).

Bizim kullandığımız model, bazı yönleri ile SNAPSS ve One-minute preceptör yöntemlerine benzese de daha kapsamlı ve sistematiktir. Model mezuniyet öncesi ve sonrasında, bireysel ve grup çalışmalarında, sınıf derslerinde, simule hasta uygulamalarında, konsey gibi çalışma ortamlarında ve sınavlarda kullanıma uygundur.

Modelin sınavlarda kullanımı için, eğitici formun olgu, bulgular ve tanı kısmını hazırladıktan sonra her aşamanın alt maddelerin cevaplarını belirler ve cevapların önemine göre puan değerlerini belirler. Bu şekilde yapılandırılmış formlar sözlü sınavlarda kullanılabilir.

\section{SONUÇ}

Klinik akıl yürütme hekimin temel yeterliği olduğu için, bu yeterliğinin sağlanabilmesi için, kurumlar kendi çerçeve/modellerini belirlemeli, eğiticiler ve öğrencilere tanıtılmalıdırlar. Ölçme ve değerlendirmede kullanılan modeller eğitim aktivitelerinde kullanılanlar ile paralellik göstermelidir. Klinik akıl yürütme modellerinin kullanılması ile gereksiz iş ve işlemlerin yapılması önlenecek, tıbbi hata yapma ihtimali azalacaktır. 


\section{Finansal Destek}

Yazarlar bu çalışma için mali destek almadıklarını beyan etmişlerdir.

\section{Çıkar Çatışması}

Yazarlar çıkar çatışması olmadığını beyan ederler.

\section{Etik Kurul}

Bu çalışma için Bakırköy Dr. Sadi Konuk Eğitim ve Araştırma Hastanesi Klinik Araştırmalar Etik Kurulundan onay alınmıştır (Karar No: 2020-12). Çalışma protokolünde, Helsinki Bildirgesi etik kuralları takip edilmiştir.

\section{KAYNAKLAR}

1. Gruppen LD. Clinical reasoning: Defining it, teaching it, assessing it, studying it. West J Emerg Med 2017;18:4-7.

2. Eva KW, Hatala RM, LeBlanc VR, Brooks LR. Teaching from the clinical reasoning literature: Combined reasoning strategies help novice diagnosticians overcome misleading information. Med Educ 2007;41:1152-8.

3. Lisa A, Kenneth D, Andrev T. Teaching clinical reasoning to medical students. Br J Hosp Med 2017;78:399-401.

4. Norman GR, Brooks LR. The non-analytical basis of clinical reasoning. Adv Heal Sci Educ 1997;2:173-84.

5. Kassirer JP. Teaching clinical reasoning: Case-based and coached. Acad Med 2010;85:1118-24.
6. Yazdani S, Hosseinzadeh M, Hosseini Fakrolsadat. Models of clinical reasoning with a focus on general practice: a critical review. J Adv Med Educ Prof 2017;5:177-84.

7. Norman G, Monteiro S, Sherbino J. Is clinical cognition binary or continuous. Acad Med 2013;88:1058-60.

8. Norman G, Sherbino J, Dore K, Wood T, Young M, Gaissmaier W, et al. The etiology of diagnostic errors: A controlled trial of system 1 versus system 2 reasoning. Acad Med 2014;89:277-84

9. Ramani S, Leinster S. AMEE guide no. 34: Teaching in the clinical environment. Med Teach 2008;30:347-64.

10. WolpawTerry, Daniel W, Papp K. SNAPPS: A Learner-centered Model for Outpatient Education. Acad Med $2003 ;: 893-8$

11. Gülpınar Mehmet Ali. İş başında/Klinikte Öğrenme, Klinik Kültür/İklim ve Olumlu Öğrenme İklimi Oluşturma. Turkiye Klin J Med Educ-Special Top 2016;1:48-58.

12. Jain V, Rao S, Jinadani M. Effectiveness of SNAPPS for improving clinical reasoning in postgraduates: Randomized controlled trial. BMC Med Educ 2019;19:1-8.

13. Neher JO, Gordon KC, Meyer B, Stevens N. A five-step "microskills" model of clinical teaching. J Am Board Fam Pract 1992;5:419-24.

14. Furney SL, Orsini AN, Orsetti KE, Stern DT, Gruppen LD, Irby DM. Teaching the one-minute preceptor: A randomized controlled trial. J Gen Intern Med 2001;16:620-4. 